\title{
CA THYROID WITH METASTASES
}

Shishir Kumar' ${ }^{1}$ Ashuthosh Chitnis², Priti Kapoor ${ }^{3}$, Rini Palve $^{4}$, Meeta Vijay ${ }^{5}$

${ }_{1}^{1}$ Resident, Department of Radiodiagnosis, Mahatma Gandhi Mission's Institute of Health Sciences, Navi Mumbai.

${ }^{2}$ Assistant Professor, Department of Radiodiagnosis, Mahatma Gandhi Mission's Institute of Health Sciences, Navi Mumbai.

${ }^{3}$ Assistant Professor, Department of Radiodiagnosis, Mahatma Gandhi Mission's Institute of Health Sciences, Navi Mumbai.

${ }^{4}$ Resident, Department of Radiodiagnosis, Mahatma Gandhi Mission's Institute of Health Sciences, Navi Mumbai.

${ }^{5}$ Resident, Department of Radiodiagnosis, Mahatma Gandhi Mission's Institute of Health Sciences, Navi Mumbai.

\section{ABSTRACT}

\section{BACKGROUND}

Thyroid malignancy occurs with relative infrequency, although benign thyroid disease is relatively common. Most primary thyroid cancer are derived from follicular or parafollicular cells. ${ }^{1}$ Follicular carcinoma affect women more than men. ${ }^{1}$ Invasive follicular carcinoma metastasises in $20-40 \%$ cases. $^{2}$ Distant metastases are seen in a minority of patients and the reported rates of occurrence range from 4 to $15 \%, 3,4,5$ We report a case of 61 yrs. female who came with chief complaints of severe headache and bilateral decreased vision. On imaging studies, which was diagnosed as skull base metastases from primary carcinoma of thyroid.

\section{KEYWORDS}

Carcinoma Thyroid, Skull Base Mets.

HOW TO CITE THIS ARTICLE: Kumar S, Chitnis A, Kapoor P, et al. CA thyroid with metastases. J. Evolution Med. Dent. Sci. 2016;5(99):7303-7304, DOI: 10.14260/Jemds/2016/1652

\section{BACKGROUND}

Thyroid malignancies are divided into papillary carcinomas (80\%), follicular carcinomas (10\%), medullary thyroid carcinomas (5 - 10\%), anaplastic carcinomas (1 - 2\%), primary thyroid lymphomas (rare) and primary thyroid sarcomas (rare). The most common site of distant metastases is the lung followed by the bone. ${ }^{6}$

Metastasis to skull base are rare phenomenon in thyroid malignancies. Skull metastasis is uncommon and is found in $2.5 \%-5.8 \%$ of cases of thyroid cancer. ${ }^{7}$

We report a case of 61 yrs. female who came with chief complaints of severe headache and bilateral decreased vision and was diagnosed as case of skull base metastases from primary carcinoma of thyroid.



\section{CASE REPORT}

Patient was 61 yrs. female, came with chief complaints of -

- Severe headache.

- Decreased bilateral vision.

- $\quad$ A NECT Head was done.

- Axial CT sections revealed a hyperdense mass lesion at skull base. This mass lesion was causing erosion of adjacent bones. There were evidence of specs of calcification within the mass.

- CECT Head was done further, which revealed it to be intensely enhancing suggesting its hypervasular nature.

Financial or Other, Competing Interest: None.

Submission 12-03-2016, Peer Review 28-11-2016,

Acceptance 05-12-2016, Published 12-12-2016.

Corresponding Author:

Dr. Shishir Kumar,

\#49-E, Surya Vihar Colony,

Takiya Kanaldah,

Gorakhpur-273015,

Uttar Pradesh.

E-mail:shishir_sai709@yahoo.in

DOI: $10.14260 /$ jemds/2016/1652

\section{(c) $(7)(5)$}

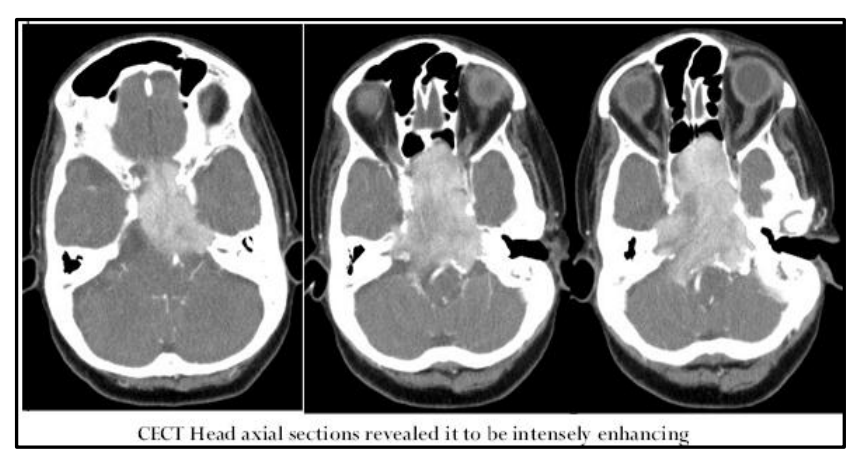

- MRI Brain plain with contrast was done.

- The lesion was mildly hyperintense on T1 weighted images; on T2 weighted images it was isointense and showed mild restriction on diffusion weighted images. On $\mathrm{T} 1$ post contrast images, it showed intense enhancement.

- There was no compression of cavernous ICA by this lesion. This lesion was extending upto foramen ovale and foramen spinosum bilaterally. 


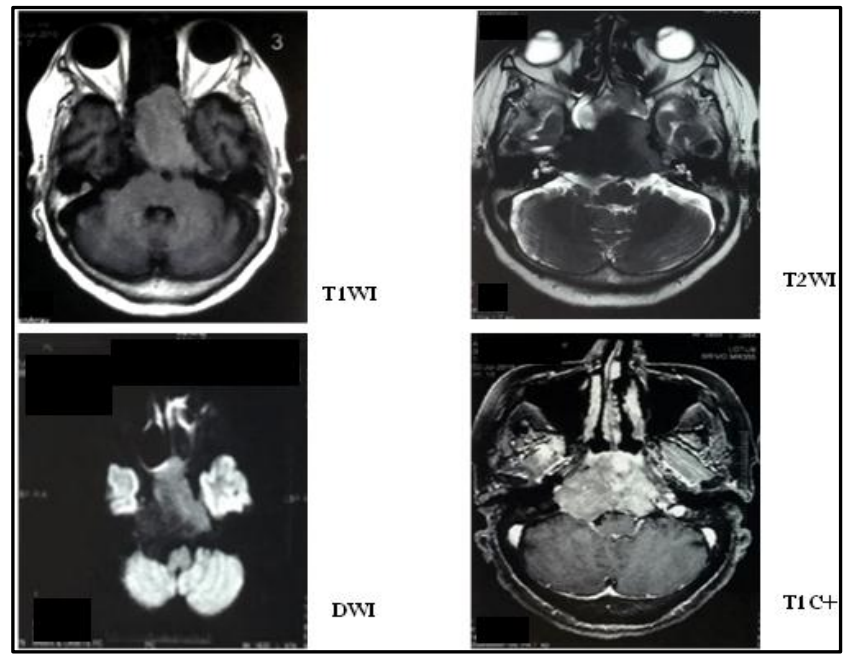

- Differentials given were -

- Chordoma.

- Chondrosarcoma.

- Metastasis.

- Excisional biopsy was done - Histopathological features suggested Metastatic Epithelial Malignancy (Possibly from Thyroid).

- A USG Thyroid was done, which revealed a hypoechoic nodule in right lobe of thyroid, which showed internal vascularity on Colour Doppler.

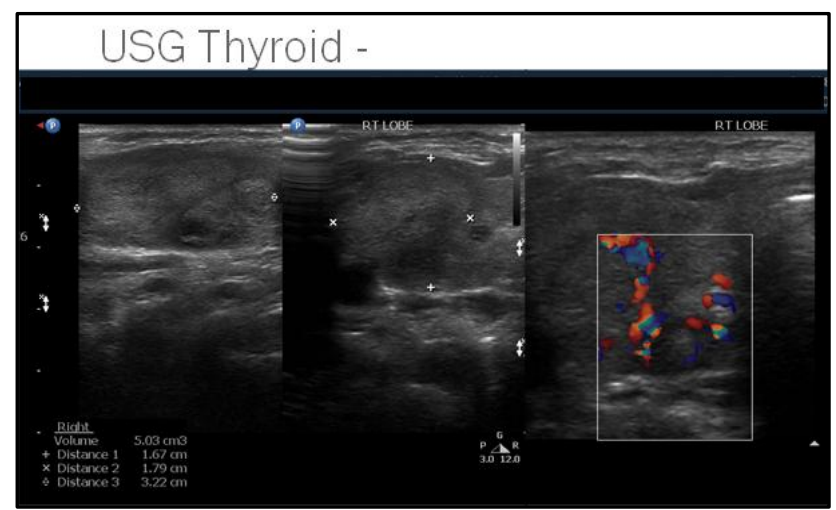

- USG-guided FNAC was done - Cytomorphological features were suggestive for Follicular Neoplasm.

- Further body imaging was done. CT Thorax revealed multiple nodules randomly distributed in bilateral lung field suggestive of cannon ball metastases.
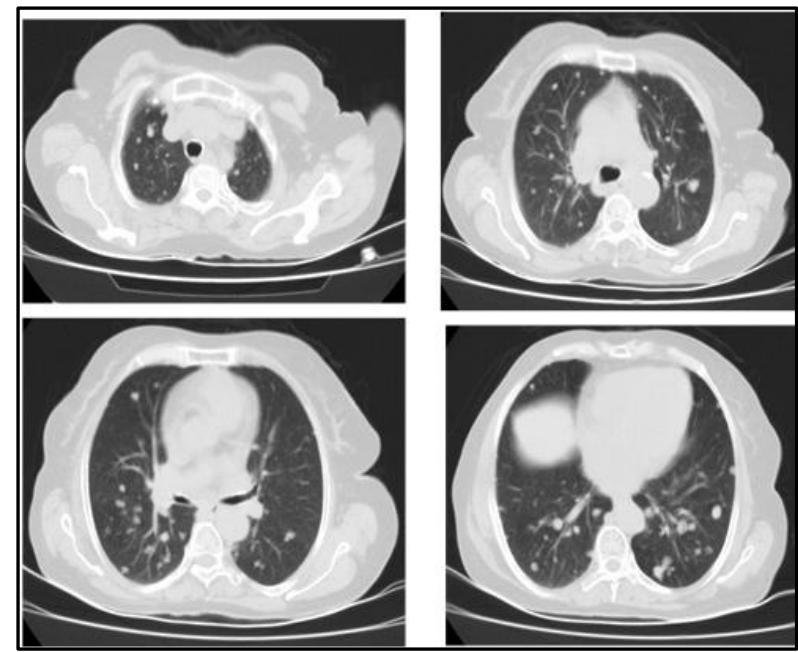

Axial Sections of CT Thorax revealing Cannon Ball Metastases

\section{DISCUSSION}

The method of spread of Thyroid Carcinoma into the skull and skull base is likely via the haematogenous route. Batson demonstrated a vertebral venous plexus, which consisted of a valveless vascular bed within the spinal canal and extended from the skull to the pelvis. ${ }^{8}$

Batson and Eckenhoff showed that there were multiple anastomoses and free connections between this venous plexus and the dural sinuses, the emissary veins of the skull as well as numerous junctions with the cervical plexus. ${ }^{9}$

Recently arterial spread has also been suggested because of the association with secondary cutaneous locations in the territory of ipsilateral external carotid artery. ${ }^{10}$

\section{Other Tumours at this Location can be} Chordoma

In the midline, nearest differential absence of any other primary in body is highly suggestive.

\section{Chondrosarcoma}

Usually off midline.

\section{CONCLUSION}

Metastases to skull base from primary thyroid malignancy is a rare entity. Imaging plays an important role in distinguishing it from other skull base lesions and establishing the primary neoplasm. It also helps in detecting other distant metastases.

\section{REFERENCES}

1. Grebe SK, Hay ID. Follicular cell-derived thyroid carcinomas. Cancer Treat Res 1997;89:90-140.

2. Hay ID, McConahey WM, Goellner JR. Managing patients papillary thyroid carcinoma: Insights gained from the Mayo clinic's experience of treating 2,512 consecutive patients during 1940 through 2000. Trans Am Clinic Climatol Assoc 2002;113:241-60.

3. Hoie J, Stenwig AE, Kullmann G, et al. Distant metastases in papillary thyroid cancer. A review of 91 patients. Cancer 1988;61(1):1-6.

4. Casara D, Rubello D, Saladini G, et al. Different features of pulmonary metastases in differentiated thyroid cancer: natural history and multivariate statistical analysis of prognostic variables. Journal of Nuclear Medicine 1993;34(10):1626-31.

5. Clark JR, Lai P, Hall F, et al. Variable predicting distant metastases in thyroid cancer. Laryngoscope 2005;115(4):661-7.

6. Mazzaferri EL, Massoll N. Management of papillary and follicular (Differentiated) thyroid cancer: new paradigms using recombinant human thyrotropin. Endocrine-Related Cancer 2002;9(4):227-47.

7. Yan B, Liu DG, Lü HL, et al. Images for diagnosis. Papillary thyroid microcarcinoma presenting as skull base metastasis. Chin Med J 2010;123(19):2750-2.

8. Baston OV. The function of the vertebral vein and their role in the spread of metastasis. Ann Surg 1940;112(1):138-49.

9. Laigle-Donadey F, Taillibert S, Martin-Duverneuil N, et al. Skull-base metastases. J Neuro Oncol 2005;75(1):63-9.

10. Portocarrero-Ortiz L, Garcia-Lopez R, Romero-Vargas S, et al. Thyroid follicular carcinoma presenting as skull and dural metastasis mimicking a meningioma: a case report. J Neurooncol 2009;95(2):281-4. 